\title{
Responses of the pest Drosophila suzukii population to environmental variables in southern Spain (Granada, Andalusia) - results of a pilot study
}

\author{
Peter Manko, J. Manuel Tierno de Figueroa \& Jozef Oboňa
}

Responses of the pest Drosophila suzukii population to environmental variables in southern Spain (Granada, Andalusia) - results of a pilot study. - Acta Mus. Siles. Sci. Natur. 70: 65-74, 2021.

\begin{abstract}
In this study conducted in Granada province in southern Spain, we analysed the flying activity and sex-ratio variability of the invasive pest Drosophila suzukii (the spotted wing drosophila) in the context of environmental factors and compared it with co-occurring Drosophilidae in a village garden. The studied D. suzukii population showed overwintering capabilities and successful maintenance in village garden with non-crop plants. Its flight period showed two peaks: female-biased, in November, and male-biased, in May. The sex ratio varied throughout the year and was mostly femalebiased. We observed the effect of temperature on Drosophilidae and rainfall and temperature on the D. suzukii. Catches of the studied species were minimal at the minimal temperatures below $0{ }^{\circ} \mathrm{C}$, and absent or near absent when the maximal temperature exceeded $30^{\circ} \mathrm{C}$. Moreover, we did not observe D. suzukii in samples when the minimum temperature below $0{ }^{\circ} \mathrm{C}$ was combined with heavy rainfall. The spotted wing drosophila seems to be more sensitive to precipitation than native Drosophilidae, as its proportion in the samples decreased with increasing rainfall. This pest also shows more pronounced short peaks in which it makes an important proportion of the biocoenosis of in comparison with other Drosophilidae.
\end{abstract}

Key words: spotted wing drosophila, seasonal activity, invasion, garden, non-crop plants

\section{Introduction}

The spotted wing drosophila - Drosophila suzukii (Matsumura 1931) (Diptera: Drosophilidae) - is a highly polyphagous and invasive primary pest that can cause significant damage to several cultivated berry and stone fruit crops (Calabria et al. 2012; Asplen et al. 2015). This species originating from Asia (Kanzawa 1939) has emerged as a major invasive insect pest of small fruits and stone fruits in both the Americas and Europe since 2008 (Asplen et al.2015). The European invasion of $D$. suzukii started in most of the Mediterranean countries in Europe and is rapidly spreading toward north and east (Goodhue et al.2011; Cini et al. 2012). The first European report is from autumn 2008 from Spain (Rasquera village, in Tarragona province) (Calabria et al. 2012), though today this species is probably already present in most of Europe. It now appears to be a subcosmopolitan species, with a distribution range between $50^{\circ} \mathrm{S}$ and $70^{\circ} \mathrm{N}$ (e.g. Hauser 2011; Lee et al. 2011; Calabria et al. 2012; Cini et al. 2012; Kiss et al. 2013; Březíková et al. 2014; Deprá et al. 2014; Kinjo et al. 2014; Asplen et al. 2015; Lengyel et al. 2015; Łabanowska \& Piotrowski 2015; Fraimout et al. 2017; Lavrinienko et al. 2017; Oboňa et al. 2017, 2019; Japoshvili et al. 2018; Ørsted \& Ørsted 2019; Zengin \& Karaca 2019; Mariychuc et al. 2020).

The lifespan of $D$. suzukii varies greatly among generations, from a few weeks to ten months (e.g. Hauser 2011; Lee et al. 2011; Calabria et al. 2012; Cini et al. 2012; Deprá et al. 2014; Kinjo et al. 2014; Asplen et al. 2015). Generations hatched earlier in the year have shorter lifespans than generations hatched after September. Only adults overwinter successfully, as was discovered in previous studies (e.g. Lee et al. 2011; Asplen et al. 2015).

Adults of D. suzukii are capable of overwintering in temperate regions (Dalton et al., 2011; Hamby et al. 2014; Kinjo et al. 2014; Zerulla et al. 2015; Rossi-Stacconi et al. 2016; Toxopeus et al. 2016) in reproductive diapause (Kanzawa 1939; Sasaki \& Sato 1995; Mitsui et al. 2010). Therefore, this species was continuously captured during the winter months in Spain (Arnó 
et al. 2016). However, the flight activity, overwintering survival rate and size of summer generations depend on the temperature (Dalton et al. 2011; Zerulla et al. 2015; Jakobs et al. 2015; Stephens et al. 2015; Arnó et al. 2016; Rossi-Stacconi et al. 2016). Variability in the sex ratio throughout the year is usually observed in studies lasting one year or longer (e.g. Dalton et al. 2011; Ometto et al. 2013; Zerulla et al. 2015; Stephens et al. 2015; Arnó et al. 2016; Rossi-Stacconi et al. 2016) because, in general, D. suzukii males are considered to be less capable than females of successfully undergoing diapause and surviving winter conditions (Dalton et al. 2011; Wiman et al. 2014).

The phenology of the species is highly variable in different climatic conditions. Despite the high number of phenological data available in the literature, research on the sensitivity of SWD to weather conditions is still a hot topic, being important from economic perspective also. Spain is one of the European countries where this species has been present for the longest time. Therefore, knowledge of its flight activity, population ecology, overwintering capabilities in an urban area garden with non-crop plants and sensitiveness to environmental factors can greatly help to better understand its ecology.

The collection of material was performed as part of a pilot study aimed at determining the species composition of insect fauna around Granada. Due to the fact that we managed to obtain a relatively large sample of $D$. suzukii from a period of one year in one trap at the site, we decided to evaluate the data obtained, despite the fact that the results are collected using a single trap. We conducted this study to contribute to the aforementioned aspects of the ecology of this important pest (flight activity, changes in sex-ratio, overwintering capabilities in an urban area garden with non-crop plants and sensitiveness to environmental factors).

\section{Material and Methods}

\section{Sampling site}

The sampling was A beer trap was located in a garden in the village Jun (Granada province, southern Spain, Latitude: $37.216211 \mathrm{~N}$; Longitude: $3.596333 \mathrm{~W} ; 762 \mathrm{~m}$ a.s.1.).

The trap was placed hanging from the branch of a quince tree (Cydonia oblonga Mill.). Trees and bushes present in the garden were Quercus coccifera L., Quercus faginea Lam., Taxus baccata L., Corylus avellana L., Laurus nobilis L., Prunus dulcis (Mill.), Cedrus atlantica (End1.) Manetti ex Carrière, Eriobotrya japonica (Thunb.) Lindl., Pistacia sp., Mespilus germanica L., Rosmarinus officinalis L., Nerium oleander L., Luma apiculate DC. Outside the garden was an extensive cultivation of olive trees (Olea europaea L.), the dominant tree species in the area, as well abundant weed and ruderal plants.

\section{Trapping and identification}

The seasonal flight activity of $D$. suzukii adults was estimated by capturing adults in beer traps. The trap was made with a durable transparent plastic bottle $(9 \mathrm{~cm}$ diameter and $30 \mathrm{~cm}$ high) with a lateral hole $(3 \mathrm{~cm}$ diameter and was baited with $330 \mathrm{ml}$ of beer. The $D$. suzukii population was monitored over ten-day periods from 18 August 2017 to 11 August 2018. The trap content was collected and filtered at the end of each 10-day period and fresh bait (beer) was subsequently put into the trap.

In the laboratory, members of Drosophilidae family were sorted and D. suzukii determined under magnification according to Bächli et al. (2004), also taking into account Calabria et al. (2012). D. suzukii can be identified based on unambiguous characters. The male has a distinct dark spot near the tip of each wing; the females do not have spotted wings. The foreleg of the male bears dark combs of cuneiform setae on the first and second tarsi. The female has a long, sharp, serrated ovipositor (e.g. Asplen et al. 2015). The number of male and female D. suzukii from each sampling period was counted under magnification.

\section{Meteorological data}

Maximum and minimum temperatures, relative humidity, wind speed and precipitation data for the study period were taken from the nearest weather station "Estación Meteorológica de IFAPA Centro Camino de Purchil" (Estaciones Agroclimáticas: Estación Meteorológica de IFAPA Centro Camino de Purchil, Granada. Consejería de Agricultura, Pesca y Desarrollo Rural. Junta de Andalucía, Spain; 37.1719444N, 3.6383333W, 630 m a.s.1., 6 km from the sampling site). The weather data were downloaded from the web site: https://www.juntadeandalucia.es/ agriculturaypesca/ifapa/ria/servlet/FrontController?action=Staticandurl=fechas.jspandc_provincia=18andc_estac ion $=101$. 
Analyses

For each sampling period, we calculated the absolute maximum ( $\mathrm{T}$ max), absolute minimum ( $\mathrm{T}$ min) and median temperature (T median); the absolute maximum ( $\mathrm{H}$ max), absolute minimum ( $\mathrm{H}$ min) and median humidity (H median); the absolute maximum ( $\mathrm{W}$ max), absolute minimum ( $\mathrm{W}$ min) and median wind speed (W median), as well as the sum of precipitation (P sum).

The correlation between each parameter and the number of individuals trapped in each period for Drosophila suzukii males, D. suzukii females, other Drosophilidae and all Drosophilidae was tested (Spearman's $\rho$ ) for the whole sampling campaign as well as for $D$. suzukii for the period from 18 October, when D. suzukii occurred in our samples for the first time, till 30 June, when maximum temperatures rose and remained above $30{ }^{\circ} \mathrm{C}$ and the median temperature was above $19^{\circ} \mathrm{C}$.

A change-point (CP) model using the change-point modelling module (Past software, v. 4.02; Hammer et al., 2001) was used to suggests positions of abrupt change (change-points) along the skew-index series. The algorithm used is Bayesian, "transdimensional" Markov chain Monte Carlo (MCMC). It produces not a single set of model parameters, but a large number as samples ("simulations") from the probability distribution (Gallagher et al. 2011).

The trends and temporal dynamics of the population sex ratio were studied by analysing the skew index along the sampling campaign. In particular, for each sampling period, we calculated the sex skew index (the difference between female and male captures divided by the total number of captures). This value varies between $1(100 \%$ females) and $-1(100 \%$ males). The sex-ratio (M:F) skew and the portion of females were analysed using the chisquared $\left(\chi^{2}\right)$ test.

\section{Results}

\section{Annual flying activity of Drosophilidae}

During the year-long sampling campaign, Drosophilidae were captured continually in beer traps during most 10-day sampling periods, even in the coldest months, except the 30-day period from 8 August till 7 September 2017 at the beginning of the sampling campaign.

The annual Drosophilidae flying activity shows two peaks - at the beginning of November and in the second half of May (Fig. 1). No captures were recorded in August and the first week of September 2017 and very small numbers of individuals were recorded in September 2017 (one to six). In October, the number of catches rose continually and reached a peak on 8 November 2017 with extreme activity increasing to 320 catches $^{\prime} 10$ days $^{-1}$, which is nearly 10-times higher than in the previous period. Immediately after reaching the peak, a huge decrease to 87 cathes $\cdot 10$ days $^{-1}$ occurred in Drosophilidae activity.

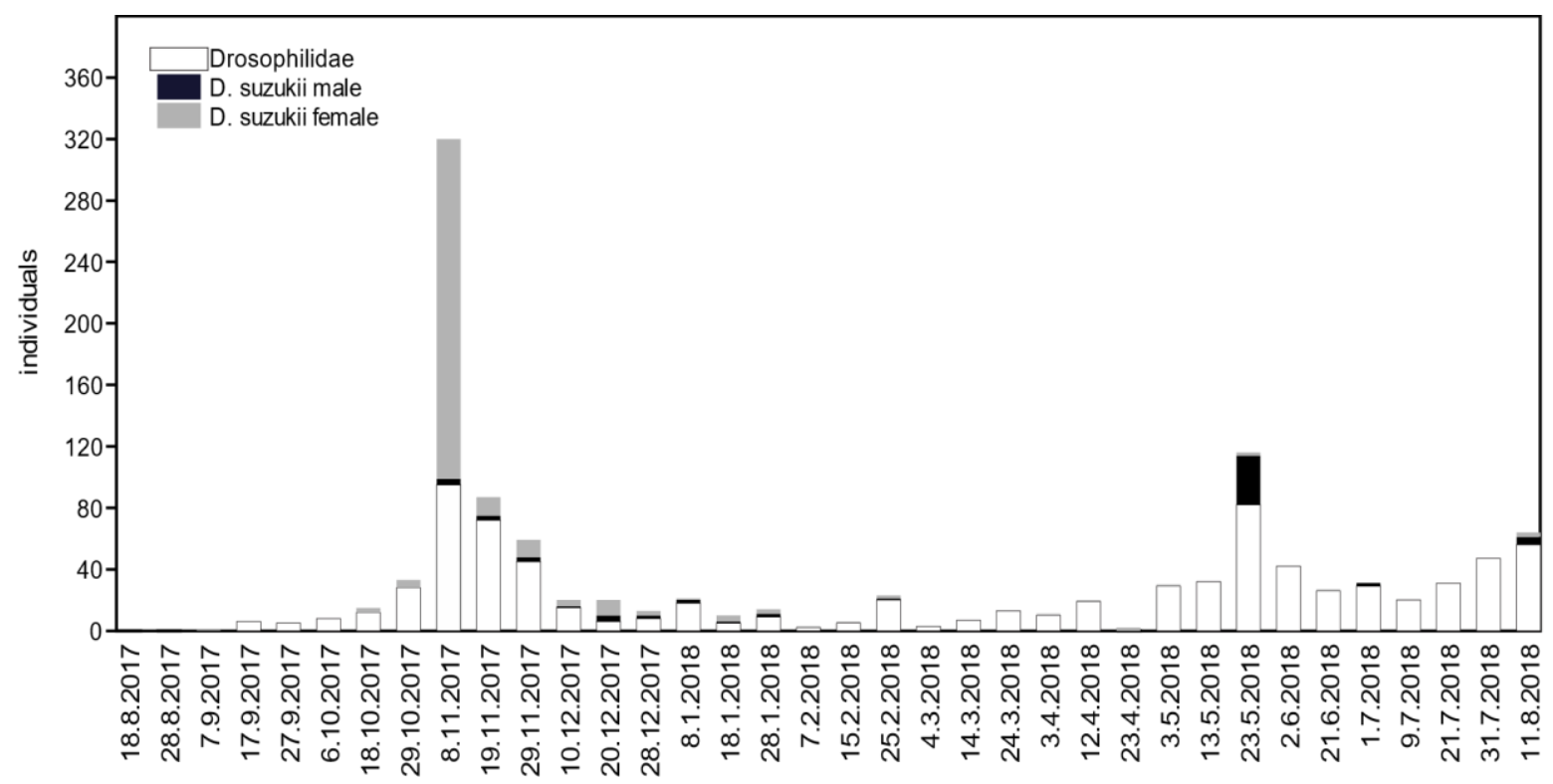

Fig 1: Number of Drosophilidae trapped during the sampling campaign (stacked chart of $D$. suzukii males, D. suzukii females and other Drosophilidae). 
In the period from December 2017 till April 2018, the flying activity was very low, but Drosophilidae constantly occurred in our samples, with population drops on 18 January, 7 February and 23 April. In May 2018, the values increased temporarily and reached a second peak on 23 May (116 catches 10 days $\left.^{-1}\right)$. After a short interim period of decreasing, the numbers captured again rose in July and August, with one drop on 9 July 2018 (Figs 1 and 3).

Annual flying activity

D. suzukii adults are active during the winter, and adult populations peaked in autumn and spring. The flying activity of $D$. suzukii is similar to that of other Drosophilidae but with a shorter flying period and shorter and more pronounced autumn and spring peaks (Fig. 1). We did not find D. suzukii in samples from the beginning of the sampling period until 18 October. The main flying activity of $D$. suzukii was concentrated in November. The peak occurred suddenly on 8 November with an extreme increase in flying activity ( 225 catches). A huge decrease in catches (to 15) followed immediately. After the peak, the activity was relatively low and D. suzukii was absent or represented with only one to three catches per sample from February until the end of July 2018 except the sample from 23 May 2018, when a second small peak followed (34 catches). In the last sample from 11 August 2018, we observed another eight catches.

\section{Sex ratio}

In general, the proportion of females captured was significantly higher than males (292 and 62 individuals, respectively), but the sex ratio varied markedly during the sampling campaign.

From the beginning of the flying period in autumn 2017 till 3 May 2018, adult captures were female-biased and the skew was statistically significant in four samples around and during the November peak (Figs 1 and 2). Only one sample, from 8 January, was male-biased (-0.33) during this period. In May 2018, the sex-ratio skew was male-biased in three of four samples where $D$. suzukii occurred, and the bias was statistically significant in one sample (the peak in May). However, only the period from July 2018 to the end of sampling was male-biased, according to the change-point model (Fig. 2). The seasonal pattern of flying activity differed between the two sexes. Females occurred 20 days before males in the autumn of 2017 and they reached a peak in the autumn. On the other hand, males reached a peak in the spring (May) after being absent from the samples for nearly three months (Figs 1 and 2). The proportion of females captured from October to 3 May was significantly higher than during the period from May to August $\left(\chi^{2}=326.37, \mathrm{df}=1, \mathrm{P}<0.001\right)$.

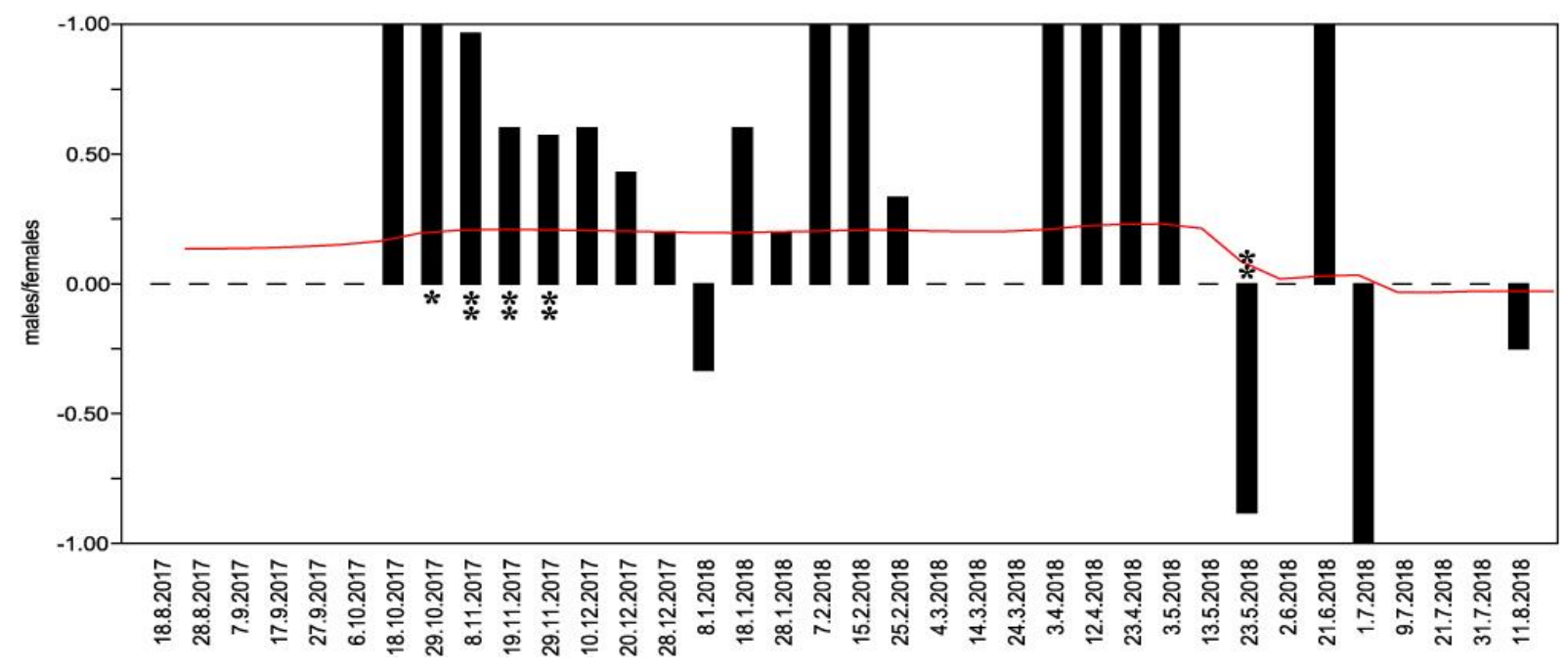

Fig 2: Sex ratio of $D$. suzukii trapped during the sampling campaign, expressed in term of male-female skew. The curve superimposed on the given data shows the average change-point model. The asterisk means a statistically significant difference $\left(\chi^{2} ; * p<0.05, * * p<0.01\right)$ of the observed sex ratio from the theoretical M:F ratio of 1:1. 


\section{Flying activity related to environmental variables}

We found a significant positive correlation between temperature (minimum, maximum, median) and the flying activity of Drosophilidae in general and Drosophilidae other than D. suzukii (Table 1).

On the other hand, we did not find a significant correlation between the flying activity of D. suzukii and available data on environmental variables (hydrometeorological records) when testing the whole sampling campaign datasets. However, we observed several significant correlations during partial periods and trends pointing to the influence of temperature and rainfall on $D$. suzukii flying activity.

Tab 1: Analysis of correlation (Spearman's $\rho$ ) between the number of individuals and the following meteorological parameters: absolute maximum ( $\mathrm{T}$ max), absolute minimum ( $\mathrm{T} \mathrm{min}$ ) and median temperature ( $\mathrm{T}$ median).

\begin{tabular}{lllll}
\hline Period & $\begin{array}{l}\text { Population } \\
\text { parameters }\end{array}$ & $\begin{array}{l}\text { Environmental } \\
\text { parameters }\end{array}$ & Spearman's $\boldsymbol{\rho}$ & $\boldsymbol{p}$ \\
\hline 18.8.17-11.8.18 & Drosophilidae & T max & 0.42 & $<0.03$ \\
(whole period) & No. of individuals & T min & 0.42 & $<0.03$ \\
& & T median & 0.44 & $<0.01$ \\
\hline 18.8.17-11.8.18 & Other Drosophilidae & T max & 0.46 & $<0.01$ \\
(whole period) & No. of individuals & T min & 0.45 & $<0.01$ \\
& & T median & 0.47 & $<0.01$ \\
\hline 7.10.17-30.6.18 & D. suzukii & T max & 0.43 & $<0.05$ \\
& No. of individuals & T min & 0.52 & $<0.01$ \\
& & T median & 0.55 & $<0.01$ \\
\hline 7.10.17-30.6.18 & D. suzukii females & T max & 0.41 & $<0.05$ \\
& No. of individuals & T min & 0.45 & $<0.03$ \\
& & T median & 0.50 & $<0.03$ \\
\hline
\end{tabular}

When testing the correlations only in the period beginning with the first occurrence of D. suzukii in the autumn ( 7 October) and ending with maximum temperatures rising constantly to more than $30^{\circ} \mathrm{C}$ and median temperatures constantly above $19^{\circ} \mathrm{C}$ (end of June), we found a significant positive correlation between the flying activity of D. suzukii and D. suzukii females and temperature, too (Tab. 1).

Moreover, during long periods with a maximum temperature higher than $30{ }^{\circ} \mathrm{C}$ and little or no precipitation, D. suzukii did not occur in samples in August to the beginning of October in 2017 and July 2018 (Fig. 3). A very small number of catches were also observed when minimal temperatures dropped below $0{ }^{\circ} \mathrm{C}$ and precipitation reached more than $30 \mathrm{~mm}$ $\mathrm{x} 10$ days $^{-1}$. No catches were recorded when minimal temperatures below $0{ }^{\circ} \mathrm{C}$ were combined with rainfall of more than $50 \mathrm{~mm}$ per sampling period. This finding is particularly visible in March 2018, when the model of change-points in precipitation also indicates a longer change in precipitation intensity. 


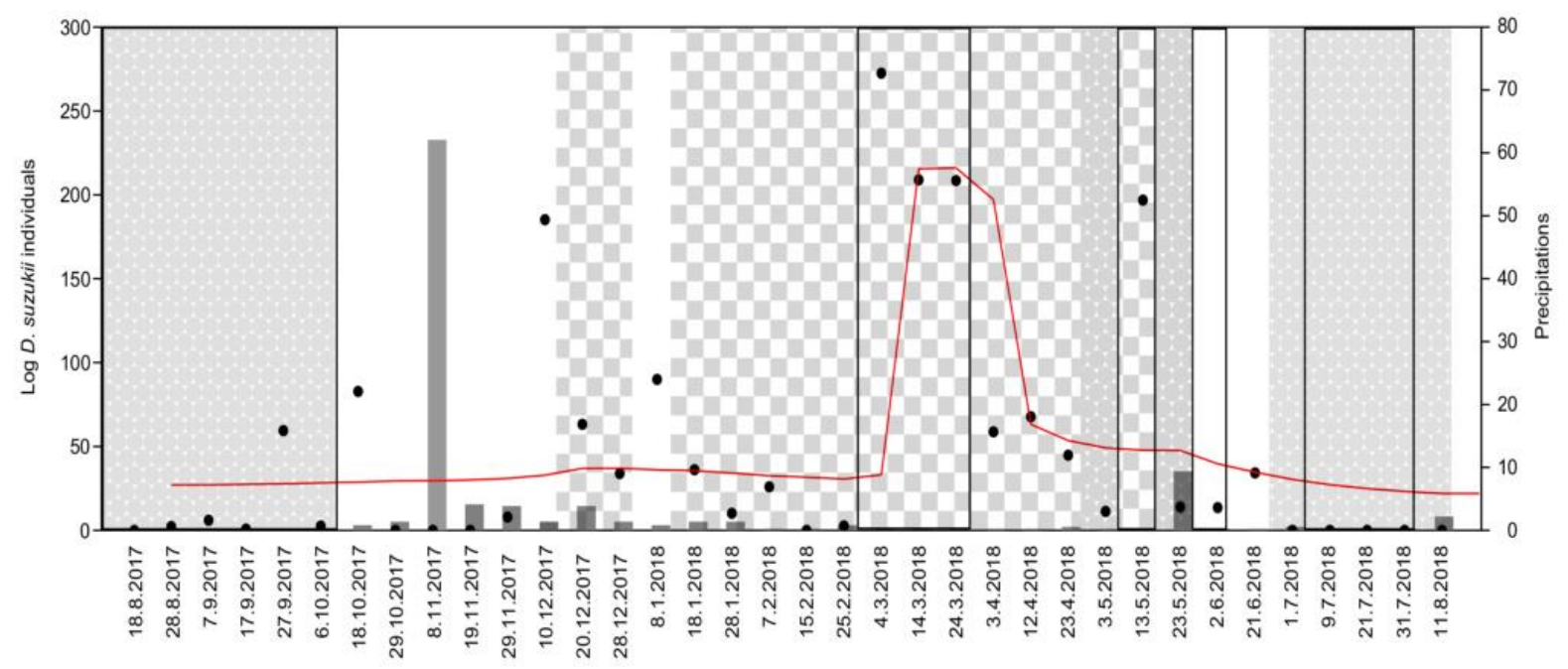

Fig 3: Flying activity of $D$. suzukii trapped (bars, primary $y$ axis) and the sum of precipitation (dots, secondary $y$ axis) during the sampling campaign. The curve superimposed on the given data shows the average change-point model of precipitation. The rectangles show the period without D. suzukii catches. Periods with minimum temperatures below $0{ }^{\circ} \mathrm{C}$ are marked by a checkerboard pattern. Periods with maximum temperatures higher than $30^{\circ} \mathrm{C}$ are marked by a circles pattern.

When analysing the data on the relative abundance of $D$. suzukii in the Drosophilidae sample, we found that the proportion of $D$. suzukii was much higher in periods with small intensity or no precipitation (Fig. 4) and, vice versa, each "peak" of D. suzukii relative abundance followed only when the rainfall intensity decreased when compared with the previous period. This indicates a much higher sensitivity to precipitation than the other Drosophilidae species occurring in the sampled area.

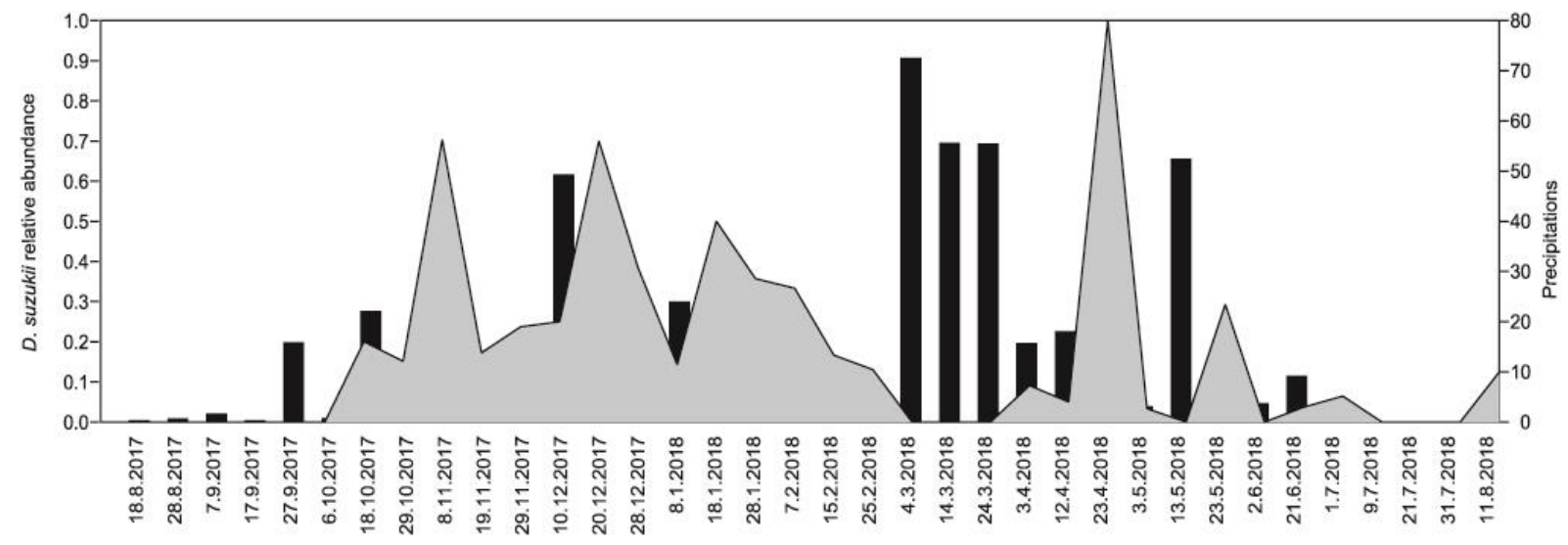

Fig 4: Portion (relative abundance) of $D$. suzukii trapped (silhouette, primary $y$ axis) and the sum of precipitation (bars, secondary $y$ axis) during the sampling campaign.

\section{Discussion}

According to our results, Drosophilidae are active during most of the year at an altitude of more than $750 \mathrm{~m}$ above sea level in southern Spain (foot of the Sierra de Huétor Mountains and close to the Sierra Nevada Mountains, province of Granada, Andalusia). The flight activity of the family Drosophilidae and D. suzukii correlates with the air temperature (minimal, 
maximal and median) and shows two peaks (in May and November) when temperatures are not extremely high or low (maximum $>30{ }^{\circ} \mathrm{C}$ and minimum $<0{ }^{\circ} \mathrm{C}$ respectively). The peaks of D. suzukii correspond with the peaks of the rest of Drosophilidae species in that area but are much more pronounced, particularly in November. In that sample, Drosophilidae females comprised about two-thirds of the Drosophilidae catches and the numbers increased up to tenfold compared to the previous period. On the other hand, the peaks of the rest of the Drosophilidae family at the site were very similar in November and May. This means that the invasive spotted wing drosophila has a different pattern of annual flying activity and dominates in the Drosophilidae community in a very short period of autumn - the first ten days of October in 2017. D. suzukii was also relatively abundant from the second half of October till the end of December and almost disappeared in February. We observed another significant portion of D. suzukii in the drosophilid community again in May, when males represented about one-third of the drosophilid catches. The difference in flying activity in August of 2017 and 2018 could indicate different patterns in 2017 and 2018. If so, the reason is unknown and may be related to the weather before the beginning of the sampling campaign and/or with the larval food (fruits) availability in different years (a combination of different factors, probably the temperature in previous winter for the most part, as harsh winters can efficiently reduce the number of overwintering individuals, which in turn will have a consequence for the population dynamics of the following generations, as Rossi-Stacconi et al. (2016) suggest).

The successful maintenance of the population in a garden surrounded by an area with extensive cultivation of olive trees is related to the capability of the spotted wing drosophila to reproduce on a wide range of common species native to the Mediterranean region, including ornamental, invasive and native non-crop plants (Lee et al., 2015; Kenis et al., 2016). Moreover, it seems that these non-crop hosts may play an important role in the maintenance of D. suzukii populations not only in natural but also in ecosystems like gardens or parks. In the case of our sampling site, in the garden (and considering also trees in neighbouring gardens although separated by a wall) it is possible to find mature fruit in all seasons. Fruits of several species present are ripening even in autumn and winter, which is usual in Mediterranean areas. Examples of trees from the sampling site ripening in the winter-early spring are first Mespilus germanica and slightly after Eriobotrya japonica. The fruit is usually left on trees or falls under them. This, we assume, forms an excellent basis for laying eggs and the developing of D. suzukii larvae. In comparison, in the northern countries, where fruit is not available in winter and early spring and the weather in winter is harsher, this species has thus far only been recorded in the autumn months (e.g. Slovakia, Czech Republic; e.g. Březíková et al. 2014; Oboňa et al. 2017). In addition to less suitable climatic conditions, the reason may be the lack of suitable fruit for laying eggs and serving as food for larvae at certain periods of the year.

It was not surprising that adults of the spotted wing drosophila were trapped even in coldest months. Arnó et al. (2016) also captured D. suzukii in January and February at average temperatures close to $0{ }^{\circ} \mathrm{C}$ in northern Spain, and other authors report females successful overwintering in other temperate areas of Italy, Japan, and North America (Dalton et al. 2011; Hamby et al. 2014; Kinjo et al. 2014; Zerulla et al. 2015; Rossi-Stacconi et al. 2016; Toxopeus et al. 2016). Rossi-Stacconi et al. (2016) confirmed overwintering in both woody and anthropic sites, and our results support the overwintering in the latter biotope.

Previous studies (Hamby et al. 2014; Harris et al. 2014; Arnó et al. 2016) based on seasonlong or longer monitoring of D. suzukii have pointed to a sharp decline in the number of captures between October and December. Our data confirm these observations and are consistent with the known relatively low cold tolerance of D. suzukii (Dalton et al. 2011; Zerulla et al. 2015; Jakobs et al. 2015; Stephens et al. 2015; Arnó et al. 2016; Rossi-Stacconi et al. 2016), indicating that repeated exposure to temperatures below $0{ }^{\circ} \mathrm{C}$ strongly correlates to the winter drop (Arnó et al. 2016). Our findings of a population developing early in the season and disappearing 
during the hottest months of the year but increasing again in autumn are similar to those published from Catalonia (Arnó et al. 2016) and other territories outside Spain (Harris et al. 2014; Wiman et al. 2014; Wang et al. 2016). High temperatures are assumed to be responsible for the population decline in summer, which should be the result of no flight activity above $24{ }^{\circ} \mathrm{C}$ reported by Kinjo et al. (2014).

We also observed the presence of a "low capture period" after the spring peak, towards the end of spring, as reported by Rossi-Stacconi et al. (2016), who supposed two possible explanations for this pattern relating to the death of most of the overwintering adults before the development of the new generation in spring oviposition hosts (Briem et al. 2016) or a sudden switch to alternative nutrient sources (e.g. pollen and nectar that would outcompete the attraction of the trap's bait).

Like other studies (e.g. Dalton et al. 2011; Ometto et al. 2013; Zerulla et al. 2015; Stephens et al. 2015; Arnó et al. 2016; Rossi-Stacconi et al. 2016), a sex-ratio variation was noticeable during the year and indicates that females are more cold-tolerant than males. Arnó et al. (2016) observed a female-bias from January to June, compared with the period of September to December in our research. Our results show a female-biased sex ratio in autumn, in winter (except for the ten days during the turn of the years) and in spring till the end of May, which differs from other studies. These differences may be caused by different climate and weather conditions in different regions (Catalonia, Barcelona NE Spain vs. Andalusia, Granada SE Spain) and locality characteristics (200 - $250 \mathrm{~m}$ a.s.1., right by the coast vs. $750 \mathrm{~m}$ a.s.1., at the foot of the Sierra de Huétor and close to the Sierra Nevada Mts.). These reasons also probably caused differences between the results of the particular studies referred to above. Of interest is the extreme difference in the sex ratio of the two peaks of $D$. suzukii in our research (as showed in Figs 1 and 2). Such a difference is unusual when compared with the results of previous studies.

While Wong et al. (2018) and our results did not support a correlation between humidity and the flight performance of $D$. suzukii, one of the most surprising results of our study was the impact of heavy precipitation. Thus far, we have not encountered a similar phenomenon in previous studies. The clear decrease of flying activity caused by precipitation and the absence of spotted wing drosophila during periods with heavy rainfall and temperatures below $0{ }^{\circ} \mathrm{C}$ is very interesting. Moreover, perhaps even more interesting is the finding that the invasive D. suzukii is much more sensitive to heavy rain than other, native species of Drosophilidae, as Figure 4 shows. The decrease of the D. suzukii portion in the Drosophilidae sample caught in rainy periods is evident and indisputable during the main flight period.

In conclusion, our results point to a possible existence relationship between temperature and flying activity and suggest the relation of heavy rainfall and low temperatures combined with rainfall on the $D$. suzukii flying activity. Moreover, it seems that the invasive spotted wing drosophila is more sensitive to these environmental factors than native Drosophila species. We confirmed the overwintering capabilities of this pest and successful maintenance of its population in a village garden with non-crop plants and described its annual flight activity and sex-ratio variability at this locality. The sensitivity of this species to environmental factors assumed by us in this paper should be proved by a more complex study. Such new knowledge would contribute to the knowledge of the possibilities of effective control and reduction of damage caused by this invasive pest.

Acknowledgement: We would especially like to thank Manuel Jesús López Rodríguez for his help by providing constructive comments on improving the manuscript and Jerguš Grohol for help with the material and data processing. This study was partly supported by the Cultural and Educational Grant Agency under the contract No. 005PU-4/2019, and by the Slovak Research and Development Agency under the contract No. APVV-16-0236. 


\section{References}

Arnó J., Solà M., Riudavets J. \& Gabarra R. (2016): Population dynamics, non-crop hosts, and fruit susceptibility of Drosophila suzukii in Northeast Spain. - Journal of Pest Science 89(3): 713-723.

Asplen M.K., Anfora G., Biondi A., Choi D.S., Chu D., Daan K.M., Gibert P., Gutierrez A.P., Hoelmer K.A., Hutchison W.D., Isaacs R., Jiang Z.-L., Karpati Z., Kimura M.T., Pascua M., Philips C.R., Plantamp C., Ponti L., Vetek G., Vogt H., Walton V.M., Yu Y., Zappala, L. \& Desneux N. (2015): Invasion biology of spotted wing Drosophila (Drosophila suzukii): a global perspective and future priorities. - Journal of Pest Science 88(3): 469-494.

Bächli G., Vilela C.R., Andersson Escher S. \& Saura A. (2004): The Drosophilidae (Diptera) of Fennoscandia and Denmark. - Fauna entomologica Scandinavica 39: 1-362.

Březíková M., Dvořák L. \& Máca J. (2014): Faunistic records from the Czech Republic 367. Diptera: Drosophilidae. - Klapalekiana 50: 247-248.

Briem F., Eben A., Gross J. \& Vogt H. (2016): An invader supported by a parasite: Mistletoe berries as a host for food and reproduction of Spotted Wing Drosophila in early spring. - Journal of Pest Science 89(3), 749759.

Calabria G., Máca J., Bachli G., Serra L. \& Pascual M. (2012): First records of the potential pest species Drosophila suzukii (Diptera: Drosophilidae) in Europe. - Journal of Applied Entomology 136: 139-147.

Cini A., Ioratti C. \& Anfora G. (2012): A review of the invasion of Drosophila suzukii in Europe and a draft research agenda for integrated pest management. - Bulletin of Insectology 65: 149-160.

Dalton D.T., Walton V.M., Shearer P.W., Walsh D.B., Caprile J. \& Is aacs R. (2011): Laboratory survival of Drosophila suzukii under simulated winter conditions of the Pacific Northwest and seasonal field trapping in five primary regions of small and stone fruit production in the United States. - Pest management science 67(11): 1368-1374.

Deprá M., Poppe J.L., Schmitz H.J., De Toni D.C. \& Valente V.L. (2014): The first records of the invasive pest Drosophila suzukii in the South American continent. - Journal of Pest Science 87: 379-383.

Fraimout A., Debat V., Fellous S., Hufbauer R.A., Foucaud J., Pudlo P., Marin J.M., Price D.K., Cattel J., Chen X., Deprá M., François Duyck P., Guedot C., Kenis M., Kimura M.T., Loeb G., Loiseau A., Martinez-Sañudo I., Pascual M., Polihronakis Richmond M., Shearer P., Singh N., Tamura K., Xuéreb A., Zhang J. \& Estoup A. (2017): Deciphering the routes of invasion of Drosophila suzukii by means of ABC random forest. - Molecular Biology and Evolution 34: 980-996.

Gallagher K., Bodin T., Sambridge M., Weiss D., Kylander M., Large D. (2011): Inference of abrupt changes in noisy geochemical records using transdimensional changepoint models. - Earth and Planetary Science Letters 311: 182-194.

Goodhue R.E., Bolda M., Farnsworth D., Williams J.C., Zalom F.G. (2011): Spotted wing drosophila infestation of California strawberries and raspberries: economic analysis of potential revenue losses and control costs. - Pest management science 67: 1396-1402.

Hammer Ø., Harper D.A.T., Ryan P.D. (2001): PAST: Paleontological statistics software package for education and data analysis. Palaeontologia Electronica 4(1), 9pp. http://palaeo-electronica.org/2001_1/past/ issue1_01.htm.

Hamby K.A., Bolda M.P., Sheehan M.E. \& Zalom F.G. (2014): Seasonal monitoring for Drosophila suzukii (Diptera: Drosophilidae) in California commercial raspberries. - Environmental entomology 43(4): 1008-1018.

Harris D. W., Hamby K.A., Wilson H.E. \& Zalom F.G. (2014): Seasonal monitoring of Drosophila suzukii (Diptera: Drosophilidae) in a mixed fruit production system. - Journal of Asia-Pacific Entomology 17(4): 857864.

Hauser M. (2011): A historic account of the invasion of Drosophila suzukii (Matsumura) (Diptera: Drosophilidae) in the continental United States, with remarks on their identification. - Pest management science 67: 1352-1357.

Jakobs R., Gariepy T.D., Sinclair B.J. (2015): Adult plasticity of cold tolerance in a continental-temperate population of Drosophila suzukii. - Journal of insect physiology 79: 1-9.

Japoshvili G., Dzneladze N., Kirkitadze G., Kiss B. \& Kaydan M.B. (2018): A new and dangerous pest for the Caucasus - Drosophila suzukii (Matsumura, 1931) (Diptera: Drosophilidae). - Annals of Agrarian Science 16(4): 464-465.

Kanzawa T. (1939): Studies on Drosophila suzukii mats. - Journal of Plant Protection Research 29: 622.

Kenis M., Tonina L., Eschen R., van der Sluis B., Sancassani M., Mori N. \& Helsen H. (2016): Noncrop plants used as hosts by Drosophila suzukii in Europe. - Journal of Pest Science 89(3): 735-748.

Kinjo H., Kunimi Y. \& Nakai M. (2014): Effects of temperature on the reproduction and development of Drosophila suzukii (Diptera: Drosophilidae). - Applied Entomology and Zoology 49: 297-304.

Kiss B., Lengyel G.D., Nagy Z., Kárpáti Z. (2013): A pettyesszárnyú muslica (Drosophila suzukii) első magyarországi előfordulása. - Növényvédelem 49: 97-99. 
Łabanowska B. \& Piotrowski W. (2015): Drosophila suzukii stwierdzona w Polsce. - Truskawka, malina, jagody 1: 16.

Lavrinienko A., Kesäniemi J., Watts P.C., Serga S., Pascual M., Mestres F. \& Kozeretska I. (2017): First record of the invasive pest Drosophila suzukii in Ukraine indicates multiple sources of invasion. - Journal of Pest Science 90(2): 421-429.

Lee J.C., Bruck D.J., Dreves A.J., Ioriatti C., Vogt H. \& Baufeld P. (2011): In focus: spotted wing drosophila, Drosophila suzukii, across perspectives. - Pest Management Science 67: 1349-1351.

Lee J.C., Dreves A.J., Cave A.M., Kawai S., Isaacs R., Miller J.C., vanTimmeren S. \& Bruck D.J. (2015): Infestation of wild and ornamental noncrop fruits by Drosophila suzukii (Diptera: Drosophilidae). Annals of the Entomological Society of America 108: 117-129.

Lengyel G.D., Orosz S., Kiss B., Lupták R. \& Kárpáti Z. (2015): New records and present status of the invasive spotted wing drosophila, Drosophila suzukii (Matsumura, 1931) (Diptera) in Hungary. - Acta Zoologica Academiae Scientiarum Hungaricae 61(1): 73-80.

Mariychuk R., Kozeretska I., Serga S., Manko P. \& Oboňa J. (2020): Current state of invasion of Drosophila suzukii (Matsumura, 1931) in Ukraine. - European Journal of Ecology 6(1): 51-57.

Mitsui H., B eppu K. \& Kimura M.T. (2010): Seasonal life cycles and resource uses of flower-and fruit-feeding drosophilid flies (Diptera: Drosophilidae) in central Japan. - Entomological Science 13(1): 60-67.

Oboňa J., Demková D., Kohútová M., Máca J., Manko P. (2017): On the occurrence of Drosophila suzukii (Matsumura, 1931) in Slovakia. - Acta Universitatis Prešoviensis Folia Oecologica 9: 5-10.

Oboňa J., Dvořák L., Haenni J.-P., Hrivniak L., Japoshvili B., Ježek J., Kerimova I., Máca J., Murányi D., Rendoš M., Słowińska I., Snegovaya N., Starý J. \& Manko P. (2019): New and interesting records of Diptera from Azerbaijan and Georgia. - Zoosystematica Rossica 28(2): 277-295.

Ometto L., Cestaro A., Ramasamy S., Grassi A., Revadi S., Siozios S., Moretto M., Fontana P., Varotto C., Pisani D., Dekker T., Wrobel N., Viola R., Pertot I., Cavalieri D., Blaxter M., Anfora G. \& Rota-Stabelli O. (2013): Linking genomics and ecology to investigate the complex evolution of an invasive Drosophila pest. - Genome biology and evolution 5(4): 745-757.

Ørsted I.V. \& Ørsted M. (2019): Species distribution models of the Spotted Wing Drosophila (Drosophila suzukii, Diptera: Drosophilidae) in its native and invasive range reveal an ecological niche shift. - Journal of Applied Ecology 56(2): 423-435.

Rossi-Stacconi M.V., Kaur R., Mazzoni V., Ometto L., Grassi A., Gottardello A., Rota-Stabelli O. \& Anfora G. (2016): Multiple lines of evidence for reproductive winter diapause in the invasive pest Drosophila suzukii: useful clues for control strategies. - Journal of pest science 89(3): 689-700.

Sasaki M. \& Sato R. (1995): Bionomics of the cherry drosophila, Drosophila suzukii Matsumura (Diptera: Drosophilidae) in Fukushima Prefecture [Japan], 3: Life cycle. Annual Report of the Society of Plant Protection of North Japan (Japan).

Stephens A.R., Asplen M.K., Hutchison W.D., Venette R.C. (2015): Cold hardiness of winter-acclimated Drosophila suzukii (Diptera: Drosophilidae) adults. - Environmental entomology 44(6): 1619-1626.

Toxopeus J., Jakobs R., Ferguson L.V., Gariepy T.D., Sinclair B.J. (2016): Reproductive arrest and stress resistance in winter-acclimated Drosophila suzukii. - Journal of insect physiology 89: 37-51.

Wang X.G., Stewart T.J., Biondi A., Chavez B.A., Ingels C., Caprile J., Grant J.A., Walton V.M. \& Daane K.M. (2016): Population dynamicsand ecology of Drosophila suzukii in Central California. - Journal of Pest Science 89: 701-712.

Wiman N.G., Walton V.M., Dalton D.T., Anfora G., Burrack H.J., Chiu J.C., Daane K.M., Grassi A., Miller B., Tochen S., Wang X. \& Ioriatti C. (2014): Integrating temperature-dependent life table data into a matrix projection model for Drosophila suzukii population estimation. - PloS one 9(9): e106909.

Wong J.S., Wallingford A.K., Loeb G.M., Lee J.C. (2018): Physiological status of Drosophila suzukii (Diptera: Drosophilidae) affects their response to attractive odours. - Journal of Applied Entomology 142(5): 473-482.

Zengin E. \& Karaca İ. (2019): Dynamics of trapped adult populations of Drosophila suzukii Matsumura (Diptera: Drosophilidae) and its parasitoids in Uşak Province, Turkey. - Egyptian Journal of Biological Pest Control 29(1): 43.

Zerulla F.N., Schmidt S., Streitberger M., Zebitz C.P. \& Zelger R. (2015): On the overwintering ability of Drosophila suzukii in South Tyrol. - Journal of Berry Research 5(1): 41-48.

Authors' addresses: Peter Manko \& Jozef Oboňa, Department of Ecology, Faculty of Humanities and Natural Sciences, University of Prešov, 17. novembra 1, 08116 Prešov, Slovakia.

*corresponding author: E-mail: peter.manko@unipo.sk

J. Manuel Tierno de Figueroa, Departamento de Zoología, Facultad de Ciencias, Campus de Fuentenueva s/n, Universidad de Granada, SP-18071, Granada, Spain. 